\title{
A contrast-enhanced-CT-based classification tree model for classifying malignancy of solid lung tumors in a Chinese clinical population
}

\author{
Xiaonan Cui ${ }^{1,2} \wedge$, Marjolein A. Heuvelmans ${ }^{3,4}$, Grigory Sidorenkov ${ }^{3}$, Yingru Zhao ${ }^{1}$, Shuxuan Fan ${ }^{1}$, \\ Harry J. M. Groen ${ }^{5}$, Monique D. Dorrius ${ }^{2}$, Matthijs Oudkerk ${ }^{6}$, Geertruida H. de Bock ${ }^{3}$, \\ Rozemarijn Vliegenthart ${ }^{2}$, Zhaoxiang Ye $^{1}$
}

${ }^{1}$ Department of Radiology, Key Laboratory of Cancer Prevention and Therapy, Tianjin Medical University Cancer Institute and Hospital, National Clinical Research Centre of Cancer, Tianjin, China; ${ }^{2}$ Department of Radiology, University Medical Center Groningen, University of Groningen, Groningen, The Netherlands; ${ }^{3}$ Department of Epidemiology, University Medical Center Groningen, University of Groningen, Groningen, The Netherlands; ${ }^{4}$ Department of Pulmonology, Medisch Spectrum Twente, Enschede, The Netherlands; ${ }^{5}$ Department of Pulmonary Diseases, University Medical Center Groningen, University of Groningen, Groningen, The Netherlands; ${ }^{6}$ Faculty of Medical Sciences, University of Groningen, Groningen, The Netherlands

Contributions: (I) Conception and design: X Cui, Z Ye, R Vliegenthart; (II) Administrative support: Z Ye, R Vliegenthart, MA Heuvelmans; (III) Provision of study materials or patients: Z Ye; (IV) Collection and assembly of data: X Cui, Y Zhao, S Fan; (V) Data analysis and interpretation: X Cui, G Sidorenkov; (VI) Manuscript writing: All authors; (VII) Final approval of manuscript: All authors.

Correspondence to: Zhaoxiang Ye, MD. Tianjin Medical University Cancer Institute and Hospital, Huan-Hu-Xi Road, Ti-Yuan-Bei, He Xi District, Tianjin 300060, China. Email: yezhaoxiang@163.com.

Background: To develop and validate a contrast-enhanced CT based classification tree model for classifying solid lung tumors in clinical patients into malignant or benign.

Methods: Between January 2015 and October 2017, 827 pathologically confirmed solid lung tumors (487 malignant, 340 benign; median size, $27.0 \mathrm{~mm}$, IQR 18.0-39.0 mm) from 827 patients from a dedicated Chinese cancer hospital were identified. Nodules were divided randomly into two groups, a training group (575 cases) and a testing group (252 cases). CT characteristics were collected by two radiologists, and analyzed using a classification and regression tree (CART) model. For validation, we used the decision analysis threshold to evaluate the classification performance of the CART model and radiologist's diagnosis (benign; malignant) in the testing group.

Results: Three out of 19 characteristics [margin (smooth; slightly lobulated/lobulated/spiculated), and shape (round/oval; irregular), subjective enhancement (no/uniform enhancement; heterogeneous enhancement)] were automatically generated by the CART model for classifying solid lung tumors. The sensitivity, specificity, PPV, NPV, and diagnostic accuracy of the CART model is $98.5 \%, 58.1 \%, 80.6 \%$, $98.6 \%, 79.8 \%$, and $90.4 \%, 54.7 \%, 82.4 \% 98.5 \%, 74.2 \%$ for the radiologist's diagnosis by using threethreshold decision analysis.

Conclusions: Tumor margin and shape, and subjective tumor enhancement were the most important CT characteristics in the CART model for classifying solid lung tumors as malignant. The CART model had higher discriminatory power than radiologist's diagnosis. The CART model could help radiologists making recommendations regarding follow-up or surgery in clinical patients with a solid lung tumor.

Keywords: Pulmonary nodules; classification tree model; prognosis; lung cancer

\footnotetext{
^ ORCID: 0000-0002-4019-6680.
} 
Submitted Apr 03, 2021. Accepted for publication Jun 25, 2021.

doi: $10.21037 /$ jtd-21-588

View this article at: https://dx.doi.org/10.21037/jtd-21-588

\section{Introduction}

The diagnosis of lung nodules is a common and expensive challenge in medicine. Chest computed tomography (CT) is widely used for lung disease diagnosis $(1,2)$. Lung nodules are divided into solid and sub-solid based on their density on CT, and the consensus of multiple guidelines is that lesions of different densities should be managed differently (3-6). Sub-solid nodules are often considered to be early stage adenocarcinoma $(6,7)$, however, the histologic types of solid nodules or tumors vary widely. The 2015 World Health Organization Classification of Lung Tumors reports there are four major histological types of solid pulmonary malignancies, including adenocarcinoma, squamous cell carcinoma, large cell carcinoma, and small cell carcinoma; and four major types of benign lesions, including pulmonary hamartoma, inflammatory myofibroblastic tumor, sclerosing pneumocytoma and granuloma (8). This brings a challenge to the stratification of solid tumors into malignant or benign based on radiological imaging.

In recent years, research has focused on the workup of smaller solid lung nodules. The Fleischner Society 2017 guidelines for the management of incidentally detected pulmonary nodules (4), advises that a solid nodule larger than $8 \mathrm{~mm}$ with suspicious morphology or upper lobe location should be considered for CT at 3 months, positron emission tomography/computed tomography (PET/CT), or tissue sampling. However, the challenge that radiologists often face is to give a definitive diagnosis of a certain nodule to be malignant or benign, especially in cancer centers where patients usually present with larger nodules or masses. Tissue biopsy is limited by difficulty to access locations and size of the tumor, and has potential complications such as pulmonary hemorrhage, pneumothorax, and risks associated with general anesthesia or sedation $(9,10)$. PET/CT and contrast-enhanced CT scan are both effective noninvasive techniques widely used in clinical practice. However, PET/CT has high requirements for equipment and increases the financial burden for patients. Therefore, a contrast-enhanced CT scan is one of the main examination techniques performed before surgery, especially in underdeveloped countries and regions (11). Prior studies have demonstrated that the level of CT enhancement can differentiate the nature of the lung tumor $(12,13)$. Absence of significant tumor enhancement $(\leq 15 \mathrm{HU})$ at contrast-enhanced CT is strongly predictive of a benign nature (11). Therefore, the use of difference in CT density between non-contrast and contrast CT may help to establish a classification model to effectively improve the diagnosis of pulmonary nodules, especially for patients with a large solid tumor considered for surgery.

Our purpose was to develop and to validate a classification tree model based on contrast-enhanced CT characteristics of solid lung tumors to differentiate between the malignant or benign nature in clinical preoperative patients.

We present the following article in accordance with the TRIPOD reporting checklist (available at https://dx.doi. org/10.21037/jtd-21-588).

\section{Methods}

The institutional ethics committee board of Tianjin Medical University Cancer Institute and Hospital (No. bc2018039) approved this study. All participants signed an informed consent form before participating in this study, and this study conformed to the provisions of the Declaration of Helsinki (as revised in 2013).

\section{Patients}

A total of 1,789 consecutive patients from Tianjin Medical University Cancer Institute and Hospital who underwent surgical resection of a lung tumor with postoperative histopathological confirmation from January 2011 to October 2017 were considered. The inclusion criteria were: (I) solitary solid lung tumor on CT (diameter $\geq 8 \mathrm{~mm}$ ); (II) preoperative thin-section non-contrast and contrastenhanced CT images $<1$ month before surgery in the Picture Archiving and Communication System (PACS); (III) postoperative pathology report; (IV) high-quality images. We excluded 411 tumor cases with sub-solid appearance on CT, all 31 small cell carcinomas based on lymph node biopsy with poorly-defined border or unmeasurable lesions, 258 cases with multiple nodules on CT, 262 patients without available preoperative CT images (mainly because of preoperative imaging at a different hospital). 


\section{Computed tomography examination}

CT examinations, consisting of an acquisition without and with iodine contrast, were performed on Somatom Sensation 64 (Siemens Medical Solutions, Forchheim, Germany) CT scanner, Lightspeed 16 (GE Medical Systems, Milwaukee, WI), or Discovery CT 750 HD (GE Medical Systems). The scan tube voltage was $120 \mathrm{kVp}$ with automatic tube current modulation. The iodine contrast agent Visipaque (Iodixanol, $270 \mathrm{mg} / \mathrm{mL}$ ) was administered intravenously through the upper extremity $(1.5 \mathrm{~mL} / \mathrm{kg}$, injection rate: $2.5 \mathrm{~mL} / \mathrm{s})$. The scan range included the pulmonary apex level to below the diaphragm, and scanning was performed 70 seconds after injection of the contrast agent. For the Siemens CT system pitch was 0.95 , acquired and reconstructed slice thickness of $1.5 \mathrm{~mm}, \mathrm{~B} 70 \mathrm{f}$ and B30 reconstruction kernels were used. Pitch for the GE CT systems was 0.984 , acquired and reconstructed slice thickness of $1.25 \mathrm{~mm}$, and Stnd and Lung reconstruction kernels were used.

\section{Evaluation of contrast-enhanced CT characteristics}

All contrast-enhanced CT scans were reviewed by two experienced radiologists (6-year and 9 year reading experience in chest CT) blindly and independently by using the RadiAnt DICOM Viewer (version 2020.2). The two radiologists determined the final radiological characteristics after a mutual consultation. The radiologists evaluated the pulmonary solid tumor on pulmonary window setting (width, 1,450 HU; level, -500 HU), and mediastinal window setting (width, $350 \mathrm{HU}$; level, $40 \mathrm{HU}$ ). Included radiological characteristics were (see detailed description and example images in Appendix 1): (I) location (left/ right; upper lobe/middle lobe/lower lobe); (II) centrality (peripheral/central); (III) shape (round/oval/irregular); (IV) margin (smooth/lobulated/spiculated); (V) calcification (yes/no); (VI) fat (yes/no); (VII) necrosis (yes/no); (VIII) cavitation (yes/no); (IX) air bronchogram (yes/no); (X) pleural indentation (yes/no); (XI) vascular invasion (yes/no); (XII) postobstructive pneumonia (yes/no); (XIII) satellite nodules (yes/no); (XIV) pleural effusion (yes/no); (XV) lymph nodes (yes/no); (XVI) size (in mm); (XVII) subjective enhancement [uniform/heterogeneous/no (<15 HU)]; (XVIII) plain CT value (in HU); (XIX) enhanced CT value (in HU); (XX) enhanced difference (in HU).

\section{Decision analysis for the radiologist's diagnosis}

We used the clinical CT report to assess the diagnostic performance of radiologist evaluation. All CT diagnostic reports were double read by two radiologists at the time of CT acquisition and assigned to one of five categories: (I) benign; (II) probably benign; (III) undetermined; (IV) probably malignant; (V) high suspicion of malignancy. These categories represent the radiologist classification of malignancy probability of the evaluated nodule in real clinical setting. In total, 27 radiologists in the radiology department were involved in CT reporting. In this study, we classified into three management groups defined the radiologist diagnosis risk thresholds based on the malignancy probability of the five categories (observe $=1$, indeterminate $=2$ or 3 or 4 , surgery $=5$ ). The "Observe" group was recommended for CT follow-up, the "indeterminate" group was recommended for further workup (short interval CT follow-up, PET-CT or biopsy), and the "surgery" group was recommended for surgery.

\section{Statistical analysis}

We randomly divided the tumors $(\mathrm{n}=827)$ into a training group $(n=575)$ and testing group $(n=252)$. Student's t-test, chi-square test, and Kolmogorov-Smirnov test were used to assess each indicator in the training and testing group. Finally, a classification and regression tree (CART) method was constructed to assess variables that might discriminate between benign and malignant tumors ( $\mathrm{P}$ value $<0.05$ in univariate analysis) (14-16). CART model builds a tree through recursive partitioning and splits data into increasingly homogeneous subgroups. At each parent node the CART algorithm picks the distinguishing variable and gives the best discriminatory cutoff value between two child nodes. The depth of the classification tree was set to automatic. The parent node stops splitting when the size is less than 15 nodes, and the child node stops splitting when the size is less than 5 nodes. To show the probability of the classification tree model, $\geq 80 \%$ probability for each node was assumed as the cut-off value. To simplify the classification tree diagram, we made concise tables. Three threshold grades (ST1, ST2, and ST3) were made to describe the malignancy probability in each child node (ST1 $=$ IF Malignant $\% \leq 20 \%$; ST2 = IF 20\% < Malignant $\%$ $<80 \%$; ST3 $=$ IF Malignant $\% \geq 80 \%)$. ST1 was classified 
Table 1 Characteristics of patients in the study

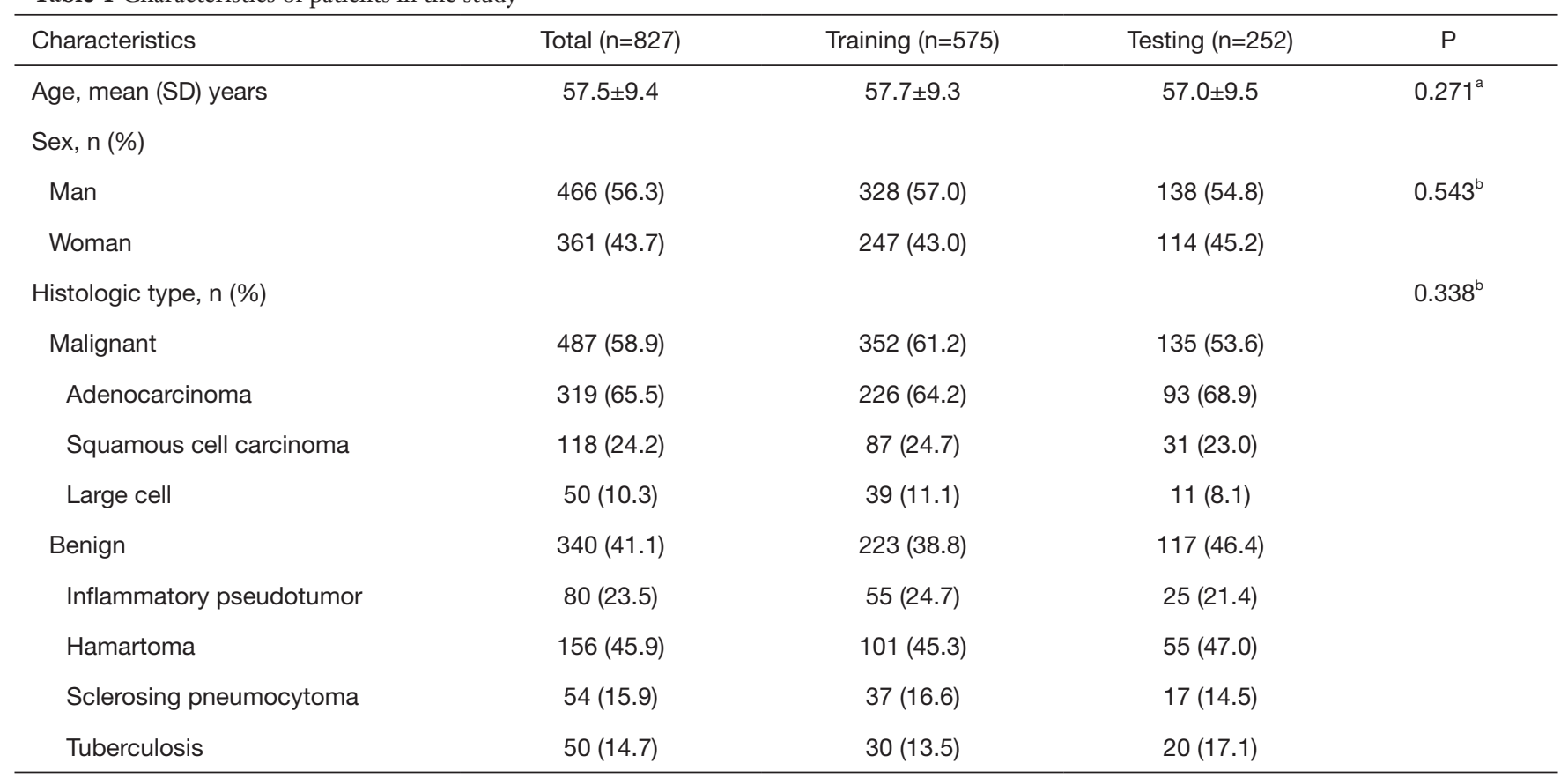

${ }^{\text {a }, ~ S t u d e n t ' s ~} t$-test (Normally distributed) and Kolmogorov-Smirnov test (non-normally distributed); ${ }^{\mathrm{b}}$, Pearson's chi-square test and Fisher's exact test. HU, Hounsfield units.

as 'observe' group, ST2 suggested for further work-up (see above), and ST3 advised for surgery, similar to the radiologist's decision (Appendix 2). Finally, we used the testing group to validate the discriminatory performance of the CART model. $\mathrm{P}<0.05$ indicated statistically significant results. Data were analysed using SPSS software version 20.0 (IBM Corp., NY, USA).

\section{Results}

\section{Lung tumor and population characteristics}

In total, 827 tumors with a median size of $27.0 \mathrm{~mm}$ (IQR 18.0-39.0 mm) in 827 patients were included. Of the patients, $56.3 \%$ were men (466/827). Mean age was 57.5 years ( $\mathrm{SD}, 9.4$ years). In total, 487 (58.9\%) lesions turned out to be malignant. The most common malignant histological type was adenocarcinoma $(n=319,65.5 \%)$, then squamous cell carcinoma $(\mathrm{n}=118,24.2 \%)$ and large cell carcinoma ( $\mathrm{n}=71,14.6 \%) ; 340(41.1 \%)$ turned out to be benign, the most common benign pathological types were hamartoma $(\mathrm{n}=156,45.9 \%)$, inflammatory pseudotumor $(\mathrm{n}=80,23.5 \%)$, sclerosing pneumocytoma $(\mathrm{n}=54,15.9 \%)$ and tuberculosis $(\mathrm{n}=50,14.7 \%)$ (Table 1$)$. We found no statistically significant differences between the training and testing group in patient and nodule characteristics.

\section{Development of the CART model for predicting malignant and benign in training group}

In the training group, nineteen variables (age, gender, nodule type, shape, margin, calcification, fat, cavitation, air bronchogram, pleural indentation, vascular invasion, postobstructive pneumonia, satellite nodules, lymph nodes, subjective enhancement, contrast-enhanced CT attenuation, plain CT attenuation, enhanced difference attenuation, size) were found to be different between the malignant and benign groups in univariate analysis (Table 2). These nineteen variables were entered into the CART model. Three categorical variables [subjective enhancement (no/uniform, heterogeneous); margin (smooth, lobulated/ spiculated); shape (round/oval, irregular)] were automatically generated by the CART (Figure 1). The optimized classification diagram was shown in Figure 2. The sensitivity, specificity, PPV (positive predictive value), NPV (negative predictive value), and diagnostic accuracy of the CART model in the training group were $94.9 \%, 57.0 \%$, $82.9 \%, 93.4 \%$, and $80.2 \%$, respectively. 
Table 2 Characteristics of benign $v s$. malignant tumors in the training group

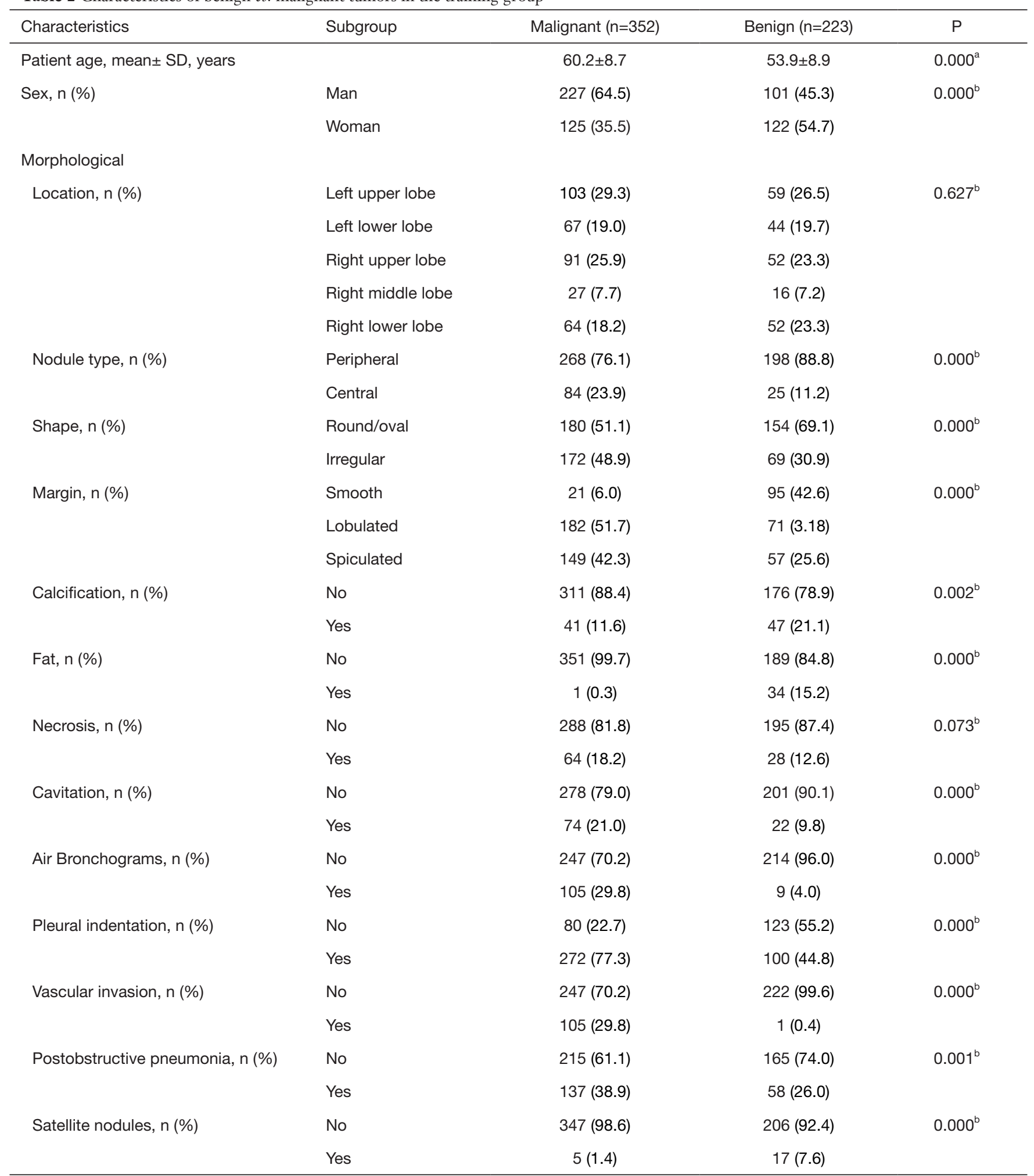

Table 2 (continued) 
Table 2 (continued)

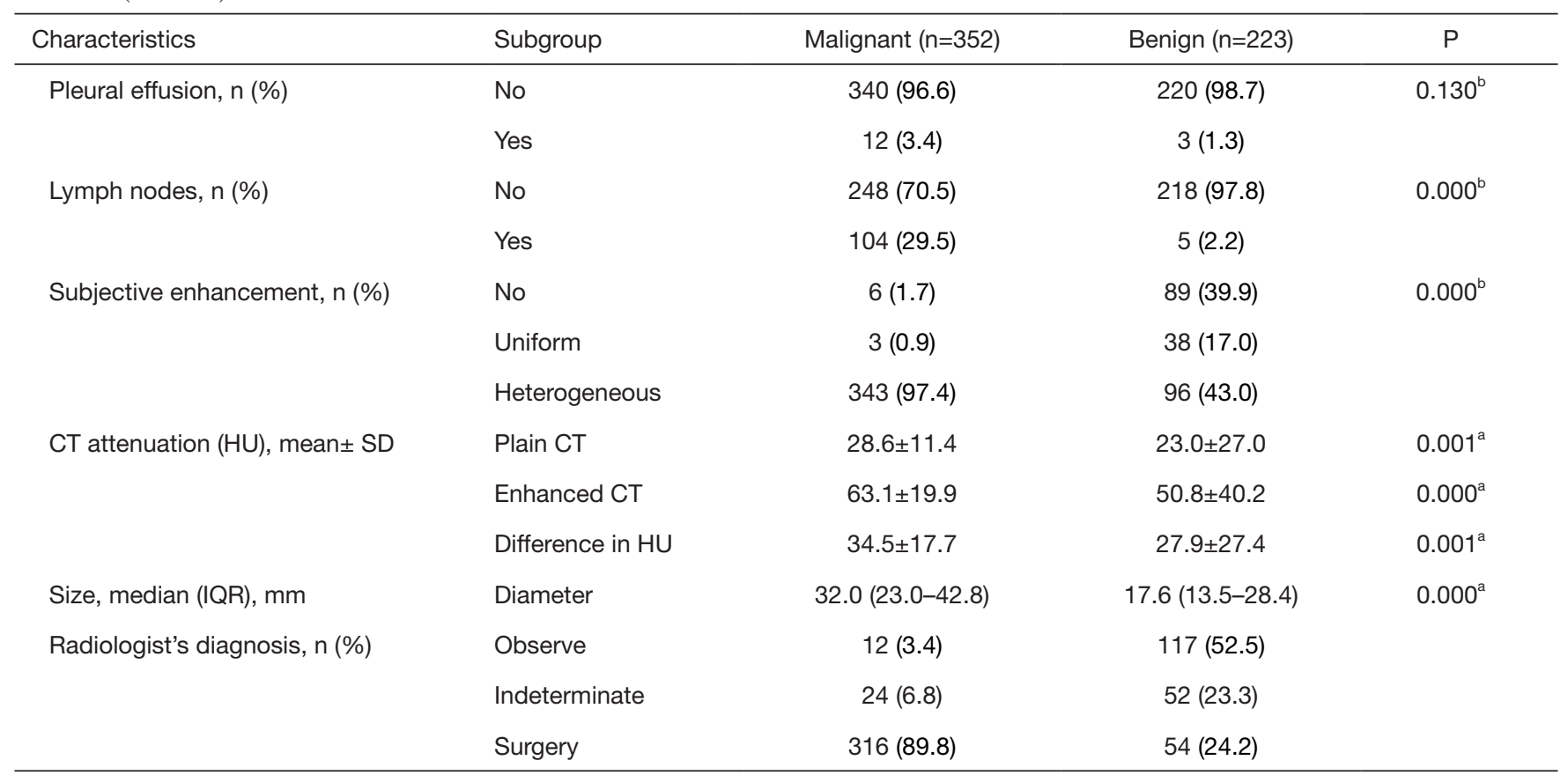

${ }^{a}$, Student's $t$-test (Normally distributed) and Kolmogorov-Smirnov test (non-normally distributed); ${ }^{\text {, }}$ Pearson's chi-square test and Fisher's exact test. HU, Hounsfield units.

\section{Validation of the CART models and radiologist's diagnosis in the testing group}

Both the radiologists and the CART model used three thresholds to determine the solid tumor malignancy risk. The classification performance of the CART models and radiologist's diagnosis were evaluated using the testing group. The sensitivity specificity, PPV, NPV, and diagnostic accuracy to differentiate malignant from benign tumors were $98.5 \%, 58.1 \%, 80.6 \%, 98.6$, and $79.8 \%$ for CART model and $90.4 \%, 54.7 \%, 82.4 \% 98.5 \%$ and $74.2 \%$ for radiologist's diagnosis, respectively (Table 3).

\section{Discussion}

Three radiological CT characteristics of solid lung lesions were shown to have discriminatory ability for malignant and benign lung tumors. These characteristics were: subjective enhancement, margin and shape. The CART model for solid tumors in our clinical population resulted in a higher diagnostic accuracy compared to radiologist's diagnosis. Our results suggest that our contrast-enhanced CT based CART model can support radiologists in making a diagnosis decision of solid lung tumors (median diameter
$27.0 \mathrm{~mm}$, IQR $18.0-39.0 \mathrm{~mm}$ ) in case only CT is available as a diagnostic tool.

Radiological characteristics (nodule type, size, shape, margin and location) and clinical information (age, gender, cancer history, smoking history) have been used to develop classification models (such as the models developed by Mayo Clinic, Brock University and Veterans Affairs) to predict the probability of malignancy of pulmonary tumors (17-19). However, several previous studies showed that the performance of these models, especially in large tumors, is moderate (20-23). Our previous study (24), comparing classification models (Veterans Affairs, Mayo, and Brock model) to the diagnosis of the radiologist for differentiation of lung nodules (median size: $17.0 \mathrm{~mm}$, IQR 13.0-21.0 $\mathrm{mm}$ ) into benign and malignant in a Chinese population, showed a lower discriminatory power for the three models compared with the radiologist's diagnosis. In that study, less than $15.5 \%$ out of 207 malignancies were classified at and above the surgical threshold using the three classification models, while the remaining malignant nodules were considered indeterminate (VA model 44.9\%, Mayo model 85.5\%; Brock model 93.7\%). The radiologist's diagnosis showed higher performance contrast to the three 


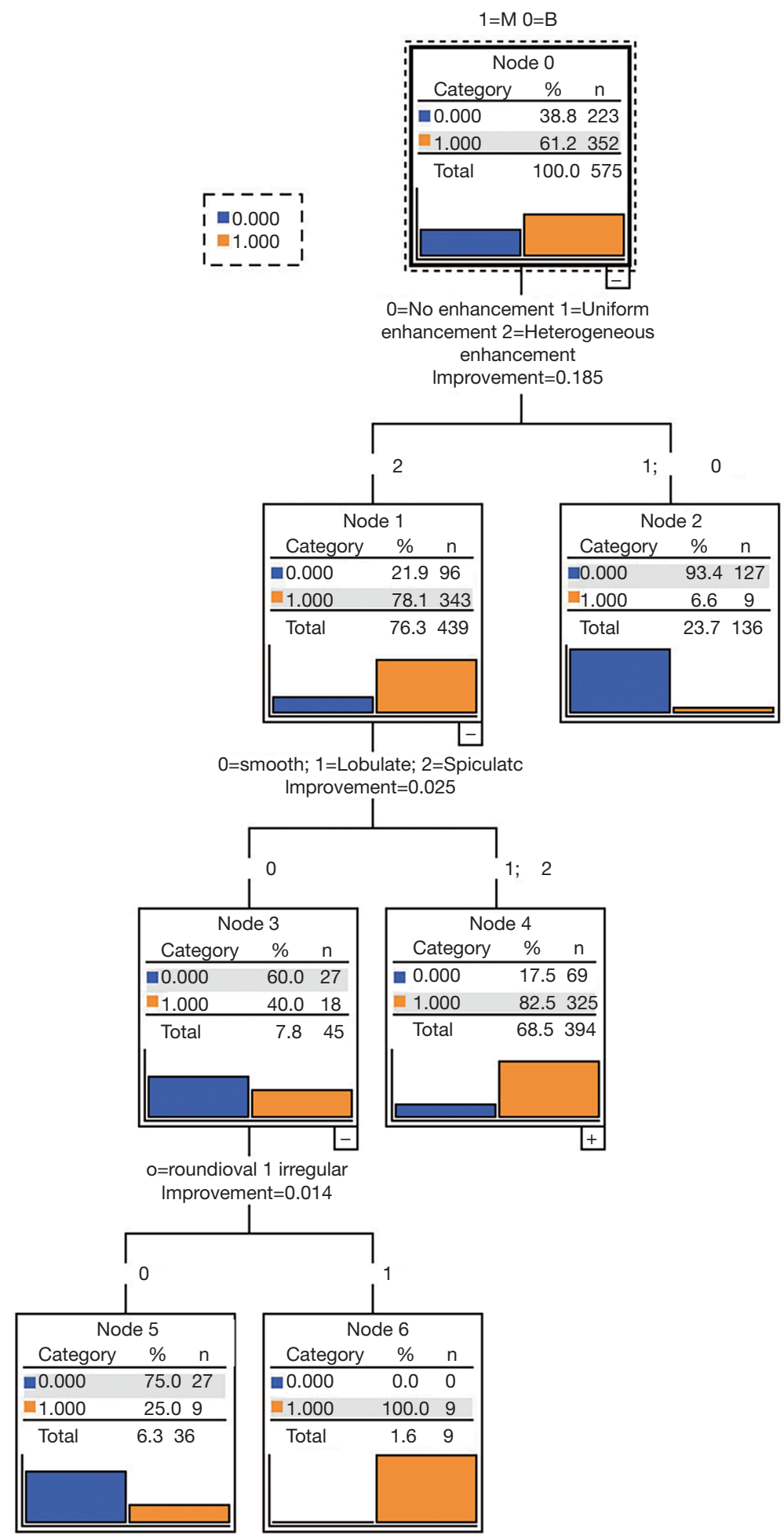

Figure 1 CART model for the classifying the malignancy of pulmonary solid tumor in the training group. CART, classification and regression tree. 


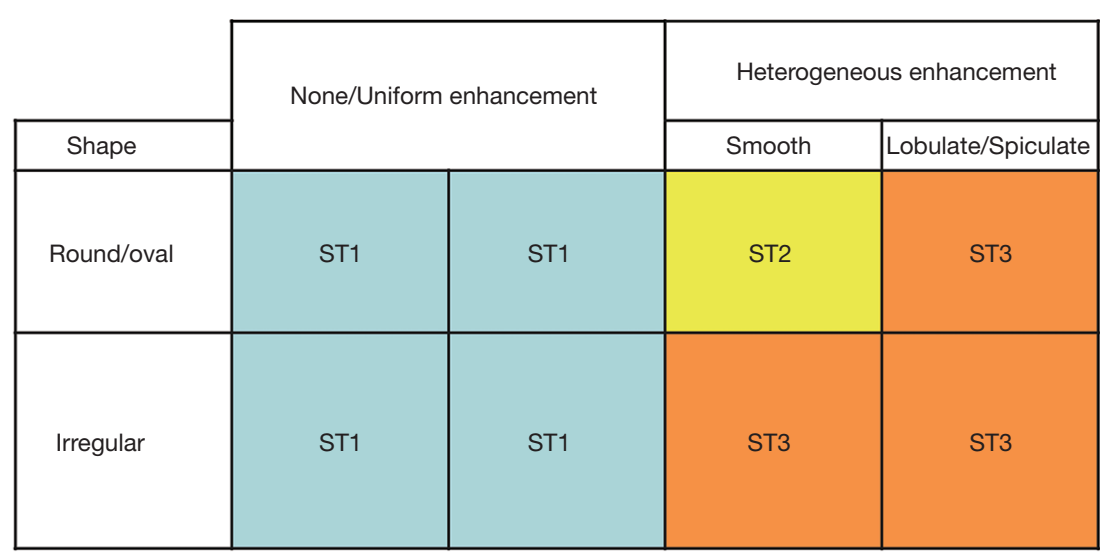

Figure 2 The optimized classification diagram of CART model (ST1 = IF Malignant $\% \leq 20 \%$; ST2 = IF 20\% < Malignant $\%<80 \%$; ST3 = IF Malignant $\% \geq 80$ ). CART, classification and regression tree.

Table 3 Decision analysis using the three thresholds in the testing group

\begin{tabular}{|c|c|c|c|c|c|c|c|}
\hline \multirow{2}{*}{$\begin{array}{l}\text { Method } \\
\text { Radiologist's diagnosis }\end{array}$} & \multirow{2}{*}{$\begin{array}{l}\text { Prediction } \\
\text { Observe }\end{array}$} & \multirow{2}{*}{$\begin{array}{c}\text { Risk threshold for } \\
\text { malignancy }\end{array}$} & \multicolumn{4}{|c|}{ Pathological results (No. \%) } & \multirow{2}{*}{$\begin{array}{c}\begin{array}{c}\text { Predictive value } \\
\text { (NPV/PPV) }\end{array} \\
98.5 \%\end{array}$} \\
\hline & & & $64(54.7)$ & T.N & $1(0.7)$ & F.N & \\
\hline & Indeterminate & $2-4$ & $27(23.1)$ & & $12(8.9)$ & & - \\
\hline & Surgery & 5 & $26(22.2)$ & F.P & $122(90.4)$ & T.P & $82.4 \%$ \\
\hline \multirow{2}{*}{ CART model } & ST2 & $20-80 \%$ & $17(14.5)$ & & $1(0.7)$ & & - \\
\hline & ST3 & $\geq 80 \%$ & $32(27.4)$ & F.P & $133(98.5)$ & T.P & $80.6 \%$ \\
\hline
\end{tabular}

P, true positive; T.N, true negative; F.P, false-positive; F.N, false-negative; NPV, negative predictive value; PPV, positive predictive value; 1 , benign; 2 , probably benign; 3 , undetermined; 4, probably malignant; 5 , high suspicion of malignancy. ST1= IF Malignant $\% \leq 20 \%$; ST2= IF $20 \%<$ Malignant $\%<80 \%$; ST3= IF Malignant $\% \geq 80 \%$.

classification models, with $8(3.9 \%)$ under the observe threshold, $42(20.3 \%)$ as indeterminate, and 157 (75.8\%) above the surgical threshold. Since the prior study only included non-contrast CT features, we decided to develop a classification model for larger tumors, based on more radiological features (contrast-enhanced CT) and the characteristics of a local population referred to a tertiary cancer center in China. In the current study, based on large lung tumors cohort, we added contrast-enhanced CT features to the traditional radiological characteristics and used a classification model (CART) instead of logistic models. Compared with the logistics regression equation, the CART model can display each step of the diagnosis more intuitively. Finally, a three thresholds ST 1-3 classification system, was used to describe the probability of malignancy of solid tumors which is more consistent with the radiologist's diagnosis process. Our results showed only $18(7.1 \%)$ tumors predicted as ST2 (indeterminate) in the CART model, compared with 39 (15.5\%) based on radiologist's diagnosis. The sensitivity and specificity were $98.5 \%$ and $58.1 \%$ for the CART model compared to $90.4 \%$ and $54.7 \%$ for the radiologist's diagnosis. Our CART model showed higher discriminatory power than radiologist's diagnosis. This suggests that contrast-enhanced CT characteristics (subjective enhancement) are useful factors for distinguishing malignant and benign pulmonary lesions.

Several previous studies showed that the lack of lung tumor CT contrast enhancement $(\leq 15 \mathrm{HU})$ is strongly predictive for benign pathology. This was found to be helpful in the discrimination of malignant and benign pulmonary lesions at contrast-enhanced CT $(12,13,25)$. The sensitivity reached $98 \%$, but the specificity for malignancy was only 
$50-60 \%$ by using $15 \mathrm{HU}$ as enhancement cut-off (13). In a study by Yi et al. (26) the sensitivity for malignant nodules was $99 \%$ with specificity of $57 \%$ by using $30 \mathrm{HU}$ as the enhancement cut-off value. The authors concluded that contrast-enhanced CT is highly sensitive to detect malignant tumors but has low specificity. The latter might be explained by the fact that some benign nodules, such as sclerosing hemangioma (27), can enhance as well. These findings are similar to our study's training group, 93.7\% $(89 / 95)$ of the lesions with no enhancement $(<15 \mathrm{HU})$, $92.7 \%$ (38/41) with uniform enhancement, and $21.9 \%$ (96/439) with heterogeneous enhancement being benign. The extent of enhancement may reflect underlying tumor angiogenesis. Therefore, radiologists cannot simply rely on an enhancement cut-off value to discriminate the benign and malignant tumors in clinical practice. In our CART model, we used subjective enhancement [(uniform, heterogeneous, no $(<15 \mathrm{HU})]$ instead of a HU cut-off value. In total, $96.4 \%(54 / 56)$ of the lesions with uniform enhancement patterns were benign. Combined with tumor shape and margin features, our CART model achieved an overall diagnostic accuracy of $79.8 \%$, which was higher than $74.2 \%$ by radiologist's diagnosis. This difference is mainly determined by the larger indeterminate malignant group in the radiologist.

There are limitations in our study. First, selection bias is unavoidable in our study. We only included surgically resected solid tumors with known pathology. This may lead to more malignancy features to be present compare to non-resected benign solid tumors. Furthermore, this is a retrospective single-center study from a dedicated Chinese cancer hospital. The clinical application of the results may require more central data to verify. Finally, the CART model should include more clinical information (smoking history, cancer history, and family history of cancer) to improve the diagnosis performance.

To conclude, a CART model based on contrast-enhanced CT characteristics was more sensitive and accurate in the classification of malignancy of solid lung tumors than radiologist's diagnosis. This classification model could assist radiologists to make recommendations regarding follow-up or surgery in clinical patients with a solid lung tumor.

\section{Acknowledgments}

Funding: This study has received funding by the Ministry of Science and Technology of the People's Republic of China National Key R\&D Program of China (grant number: No.
2018YFC1315600 and No. 2016YFE0103000), the Royal Netherlands Academy of Arts and Sciences (grant number. PSA_SA_BD_01), and the University Medical Center Groningen PhD Scholarship program.

\section{Footnote}

Reporting Checklist: The authors have completed the TRIPOD reporting checklist. Available at https://dx.doi. org/10.21037/jtd-21-588

Data Sharing Statement: Available at https://dx.doi. org/10.21037/jtd-21-588

Peer Review File: Available at https://dx.doi.org/10.21037/ jtd-21-588

Conflicts of Interest: All authors have completed the ICMJE uniform disclosure form (available at https://dx.doi. org/10.21037/jtd-21-588). The authors have no conflicts of interest to declare.

Ethical Statement: The authors are accountable for all aspects of the work in ensuring that questions related to the accuracy or integrity of any part of the work are appropriately investigated and resolved. The institutional ethics committee board of Tianjin Medical University Cancer Institute and Hospital (No. bc2018039) approved this study. All participants signed an informed consent form before participating in this study. This study conformed to the provisions of the Declaration of Helsinki (as revised in 2013).

Open Access Statement: This is an Open Access article distributed in accordance with the Creative Commons Attribution-NonCommercial-NoDerivs 4.0 International License (CC BY-NC-ND 4.0), which permits the noncommercial replication and distribution of the article with the strict proviso that no changes or edits are made and the original work is properly cited (including links to both the formal publication through the relevant DOI and the license). See: https://creativecommons.org/licenses/by-nc-nd/4.0/.

\section{References}

1. Oudkerk M, Devaraj A, Vliegenthart R, et al. European position statement on lung cancer screening. Lancet Oncol 2017;18:e754-66.

2. National Lung Screening Trial Research Team; Aberle 
DR, Adams AM, et al. Reduced lung-cancer mortality with low-dose computed tomographic screening. N Engl J Med 2011;365:395-409.

3. Zhou Q, Fan Y, Wang Y, et al. China National Guideline of Classification, Diagnosis and Treatment for Lung Nodules (2016 Version). Zhongguo Fei Ai Za Zhi 2016;19:793-8.

4. MacMahon H, Naidich DP, Goo JM, et al. Guidelines for Management of Incidental Pulmonary Nodules Detected on CT Images: From the Fleischner Society 2017. Radiology 2017;284:228-43.

5. Lung CT Screening Reporting \& Data System (LungRADS). Available online: https://www.acr.org/ClinicalResources/Reporting-and-Data-Systems/Lung-Rads

6. Callister ME, Baldwin DR, Akram AR, et al. British Thoracic Society guidelines for the investigation and management of pulmonary nodules. Thorax 2015;70 Suppl 2:ii1-ii54.

7. Travis WD, Brambilla E, Noguchi M, et al. International association for the study of lung cancer/american thoracic society/european respiratory society international multidisciplinary classification of lung adenocarcinoma. J Thorac Oncol 2011;6:244-85.

8. Travis WD, Brambilla E, Nicholson AG, et al. The 2015 World Health Organization Classification of Lung Tumors: Impact of Genetic, Clinical and Radiologic Advances Since the 2004 Classification. J Thorac Oncol 2015;10:1243-60.

9. Ozeki N, Iwano S, Taniguchi T, et al. Therapeutic surgery without a definitive diagnosis can be an option in selected patients with suspected lung cancer. Interact Cardiovasc Thorac Surg 2014;19:830-7.

10. Merritt RE, Shrager JB. Indications for surgery in patients with localized pulmonary infection. Thorac Surg Clin 2012;22:325-32.

11. Cui X, Han D, Heuvelmans MA, et al. Clinical characteristics and work-up of small to intermediate-sized pulmonary nodules in a Chinese dedicated cancer hospital. Cancer Biol Med 2020;17:199-207.

12. Schillaci O, Travascio L, Bolacchi F, et al. Accuracy of early and delayed FDG PET-CT and of contrastenhanced CT in the evaluation of lung nodules: a preliminary study on 30 patients. Radiol Med 2009;114:890-906.

13. Swensen SJ, Viggiano RW, Midthun DE, et al. Lung nodule enhancement at CT: multicenter study. Radiology 2000;214:73-80.

14. Yang Z, Dong L, Zhang Y, et al. Prediction of Severe
Acute Pancreatitis Using a Decision Tree Model Based on the Revised Atlanta Classification of Acute Pancreatitis. PLoS One 2015;10:e0143486.

15. Kim YH, Kim MJ, Shin HJ, et al. MRI-based decision tree model for diagnosis of biliary atresia. Eur Radiol 2018;28:3422-31.

16. Cui X, Heuvelmans MA, Fan S, et al. A Subsolid Nodules Imaging Reporting System (SSN-IRS) for Classifying 3 Subtypes of Pulmonary Adenocarcinoma. Clin Lung Cancer 2020;21:314-325.e4.

17. Swensen SJ, Silverstein MD, Ilstrup DM, et al. The probability of malignancy in solitary pulmonary nodules. Application to small radiologically indeterminate nodules. Arch Intern Med 1997;157:849-55.

18. McWilliams A, Tammemagi MC, Mayo JR, et al. Probability of cancer in pulmonary nodules detected on first screening CT. N Engl J Med 2013;369:910-9.

19. Gould MK, Ananth L, Barnett PG, et al. A clinical model to estimate the pretest probability of lung cancer in patients with solitary pulmonary nodules. Chest 2007;131:383-8.

20. Isbell JM, Deppen S, Putnam JB Jr, et al. Existing general population models inaccurately predict lung cancer risk in patients referred for surgical evaluation. Ann Thorac Surg 2011;91:227-33; discussion 233.

21. Perandini S, Soardi GA, Motton M, et al. Limited value of logistic regression analysis in solid solitary pulmonary nodules characterization: a single-center experience on 288 consecutive cases. J Surg Oncol 2014;110:883-7.

22. Iaccarino JM, Simmons J, Gould MK, et al. Clinical Equipoise and Shared Decision-making in Pulmonary Nodule Management. A Survey of American Thoracic Society Clinicians. Ann Am Thorac Soc 2017;14:968-75.

23. Tanner NT, Porter A, Gould MK, et al. Physician Assessment of Pretest Probability of Malignancy and Adherence With Guidelines for Pulmonary Nodule Evaluation. Chest 2017;152:263-70.

24. Cui X, Heuvelmans MA, Han D, et al. Comparison of Veterans Affairs, Mayo, Brock classification models and radiologist diagnosis for classifying the malignancy of pulmonary nodules in Chinese clinical population. Transl Lung Cancer Res 2019;8:605-13.

25. Choi Y, Gil BM, Chung MH, et al. Comparing attenuations of malignant and benign solitary pulmonary nodule using semi-automated region of interest selection on contrast-enhanced CT. J Thorac Dis 2019;11:2392-401. 
26. Yi CA, Lee KS, Kim EA, et al. Solitary pulmonary nodules: dynamic enhanced multi-detector row CT study and comparison with vascular endothelial growth factor and microvessel density. Radiology
2004;233:191-9.

27. Doyle DJ, Khalili K, Guindi M, et al. Imaging features of sclerosed hemangioma. AJR Am J Roentgenol 2007;189:67-72.
Cite this article as: Cui $\mathrm{X}$, Heuvelmans MA, Sidorenkov G, Zhao Y, Fan S, Groen HJM, Dorrius MD, Oudkerk M, de Bock GH, Vliegenthart R, Ye Z. A contrast-enhanced-CTbased classification tree model for classifying malignancy of solid lung tumors in a Chinese clinical population. J Thorac Dis 2021;13(7):4407-4417. doi: 10.21037/jtd-21-588 

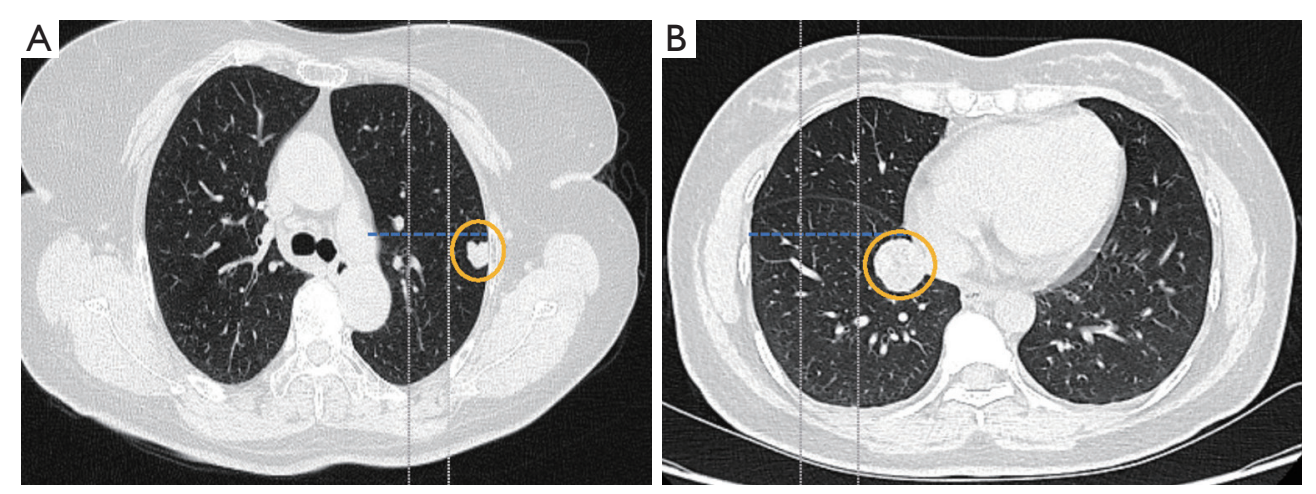

Figure S1 Distance to costal pleura (peripheral/non-peripheral). (A) Peripheral nodules: The distance to costal pleural was $<1 / 3$ from total distance hilum-costal pleura; (B) non-peripheral: the distance to costal pleural was $>1 / 3$ from total distance hilum-costal pleura.

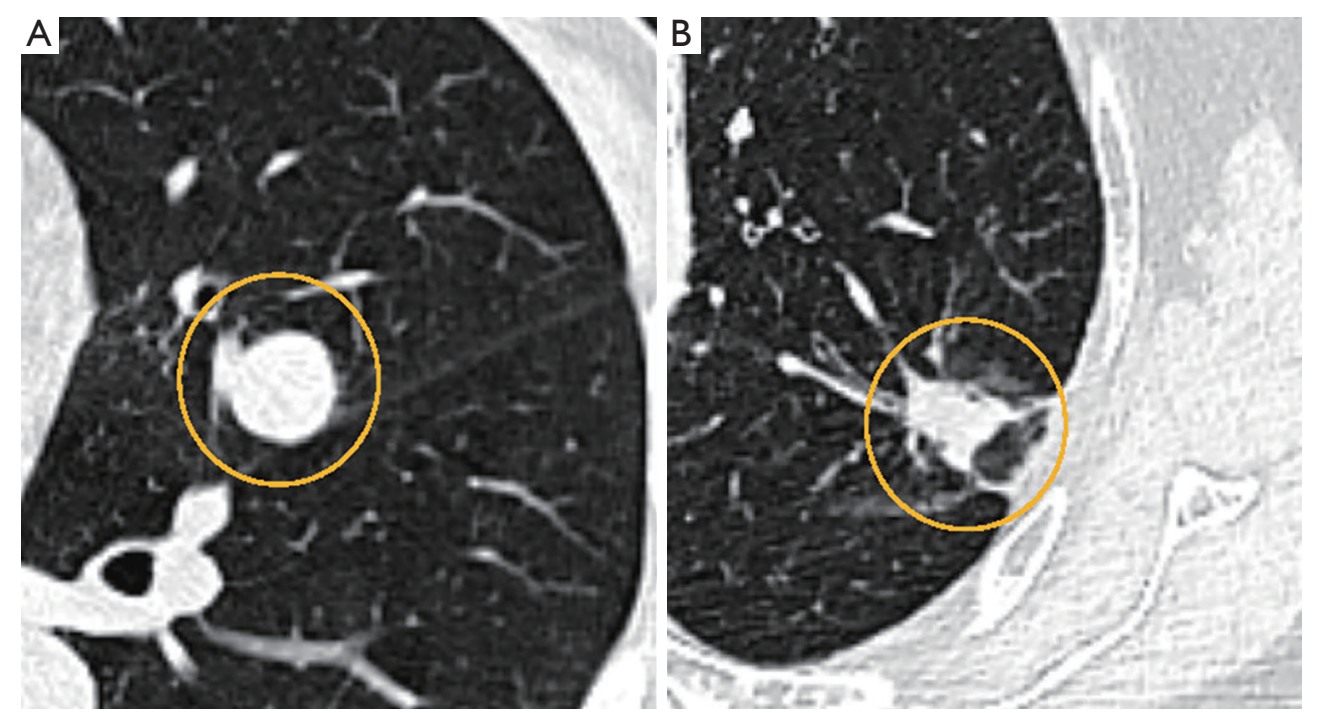

Figure S2 Shapes (round/oval, irregular). (A) Round/Oval; (B) irregular.

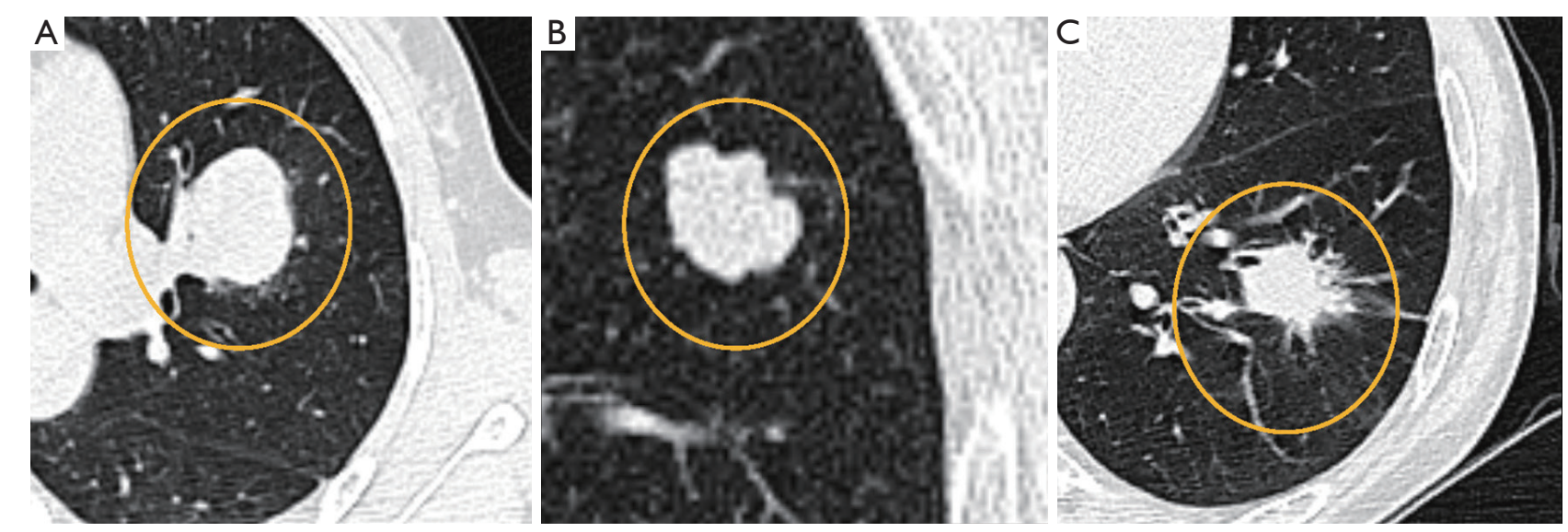

Figure S3 Margins (smooth, lobulated, spiculated). (A) Smooth; (B) lobulated; (C) spiculated.

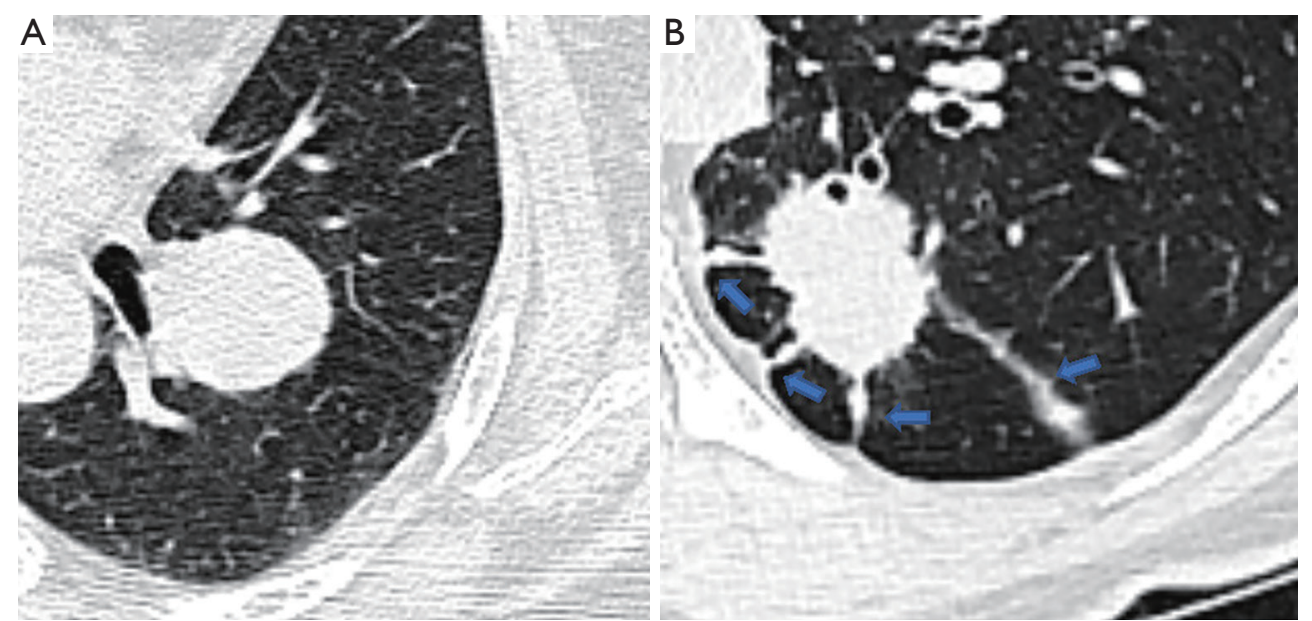

Figure S4 Pleural indentation. (A) There is no pleural indentation; (B) nodules adhering to pleura or pleural indentation with $>1$ stripe (blue arrows). 

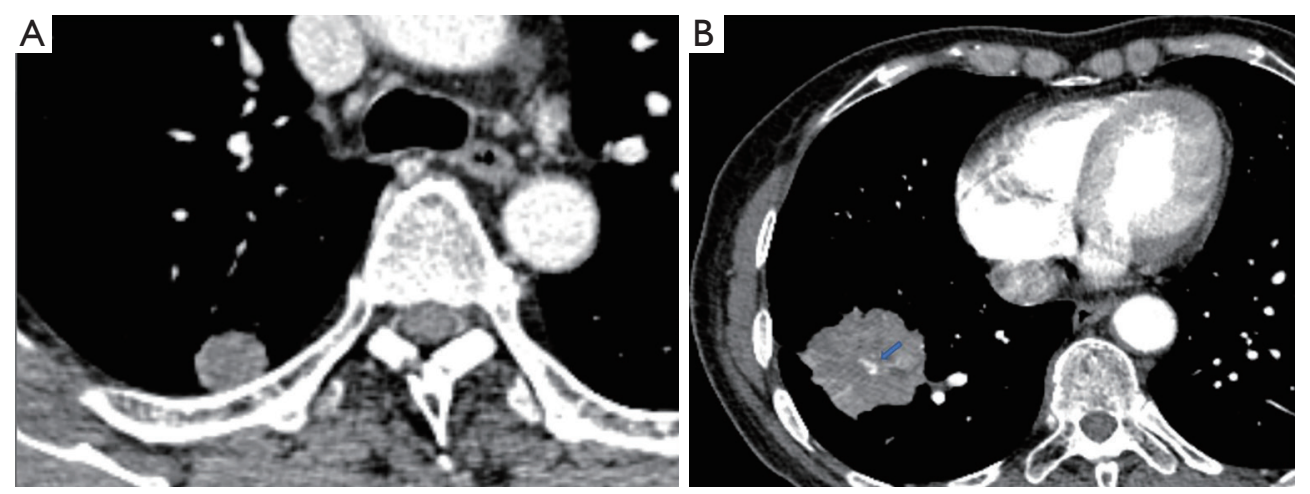

Figure S5 Vascular invasion. (A) There is no vascular invasion; (B) coexistence of irregular vascular dilation or vascular convergence from multiple supplying vessels (blue arrow).
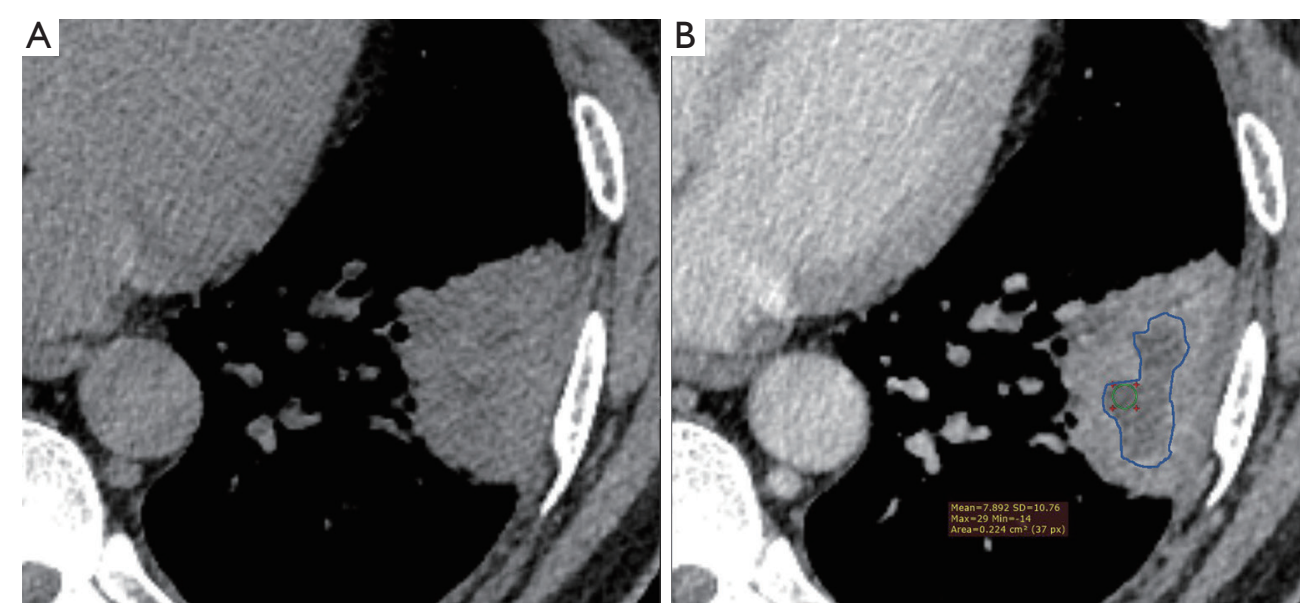

Figure S6 Necrosis. Non-enhanced liquid area after enhancement (blue area).
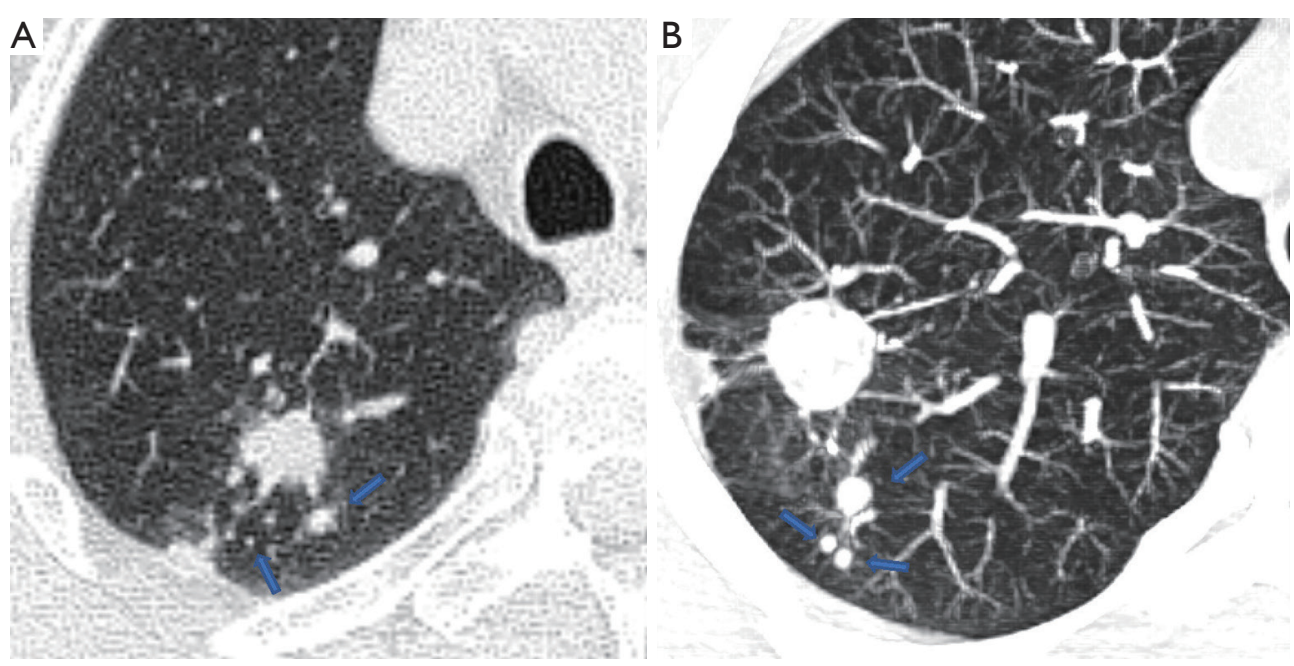

Figure S7 Satellite nodules. Satellite nodules appear around the tumor (blue arrow)
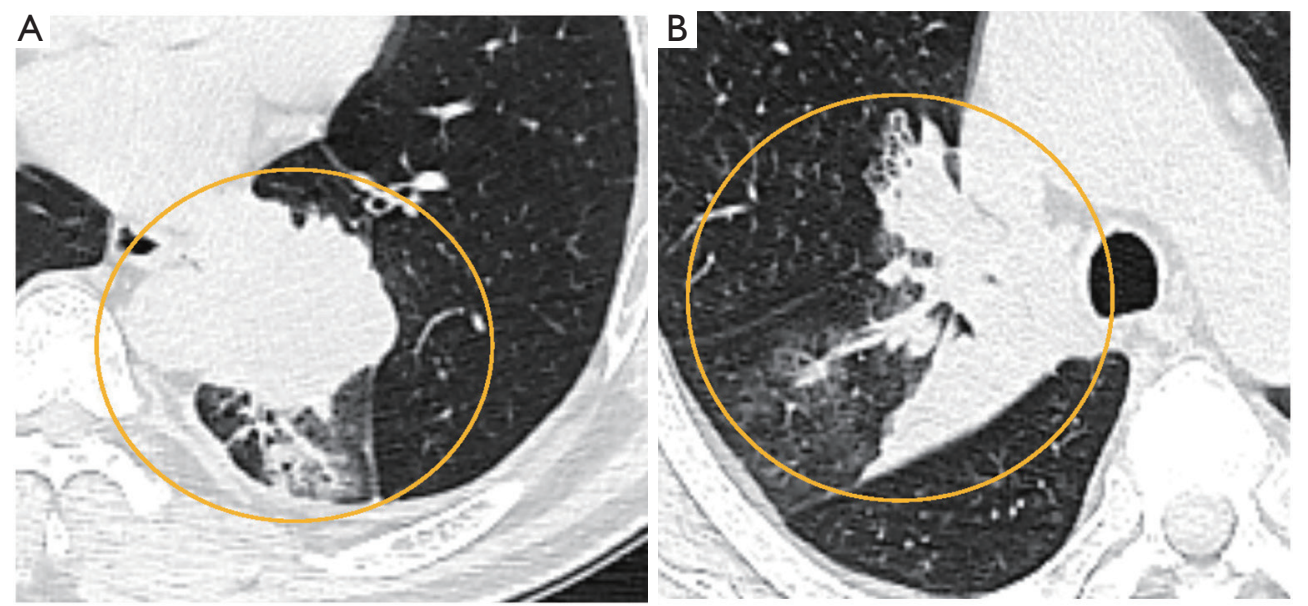

Figure S8 Postobstructive pneumonia. Ground glass infiltration and atelectasis around tumor. 


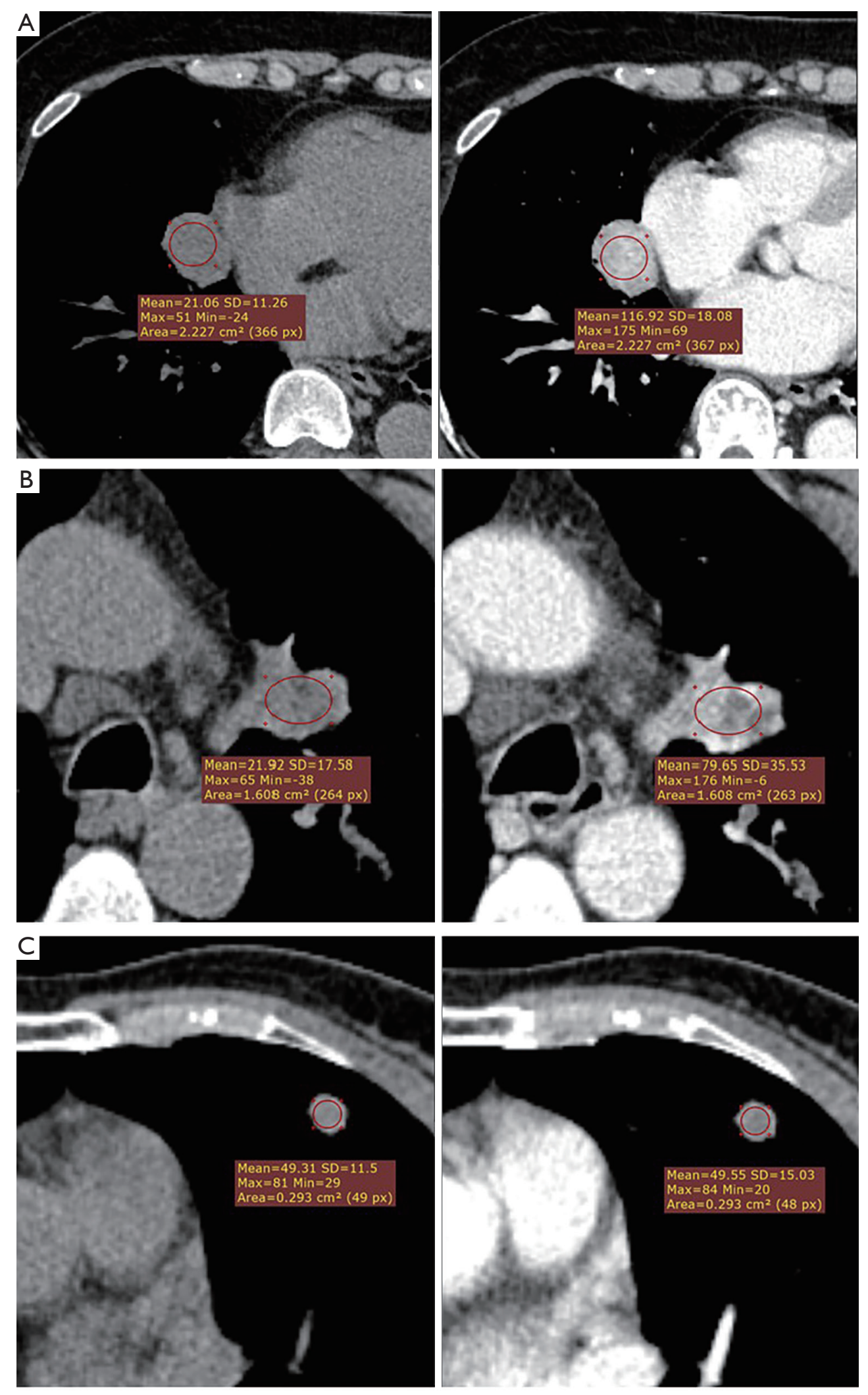

Figure S9 Subjective enhancement (uniform/heterogeneous/no). (A) The tumor enhanced difference is large than $15 \mathrm{HU}$ with uniform enhancement; (B) the tumor enhanced difference is large than $15 \mathrm{HU}$ with heterogeneous enhancement; (C) the tumor enhanced difference is less than $15 \mathrm{HU}$. 


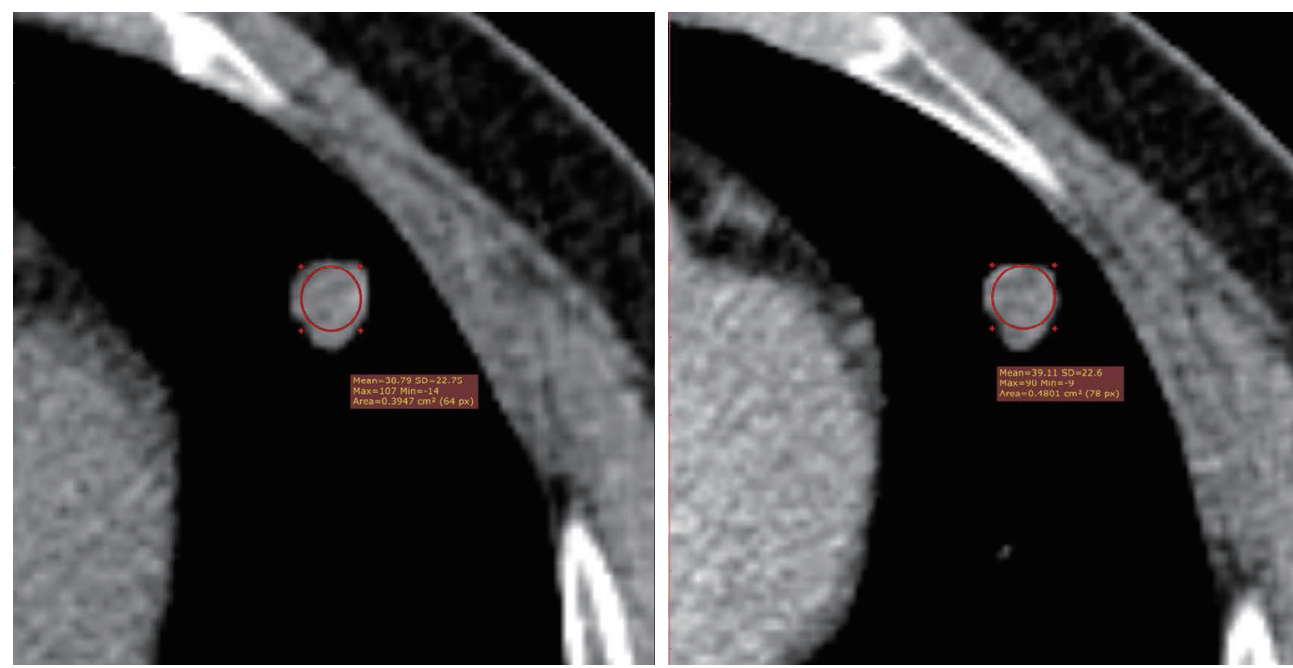

Figure S10 A 42 years old male patient with a solid oval, slightly lobulated tumor $\left(15 \times 14 \mathrm{~mm}^{2}\right)$ located in the left upper lobe. The mean density of the nodule was 38.8 Hounsfield Units on 5 CT without iodine contrast, and 39.1 Hounsfield Units after contrast (no enhancement). Radiologist's diagnosis: Benign; CART model classification: ST1; Histology: hamartoma.
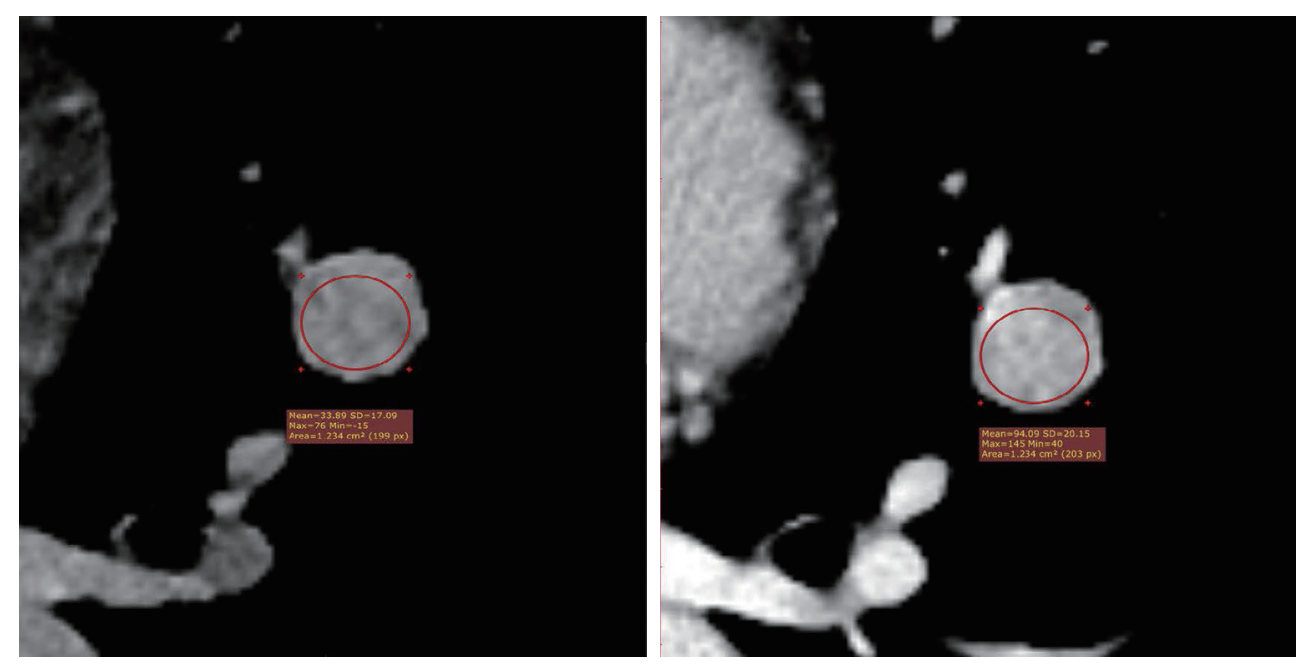

Figure S11 A 53 years old female patient with a solid round, smooth tumor $\left(22 \times 21 \mathrm{~mm}^{2}\right)$ located in the left lower lobe. The mean density of the nodule was 33.9 Hounsfield Units on CT without iodine contrast, and 94.1 Hounsfield Units after contrast (uniform-enhancement). Radiologist's diagnosis: Benign; CART model classification: ST1; Histology: sclerosing pneumocytoma.

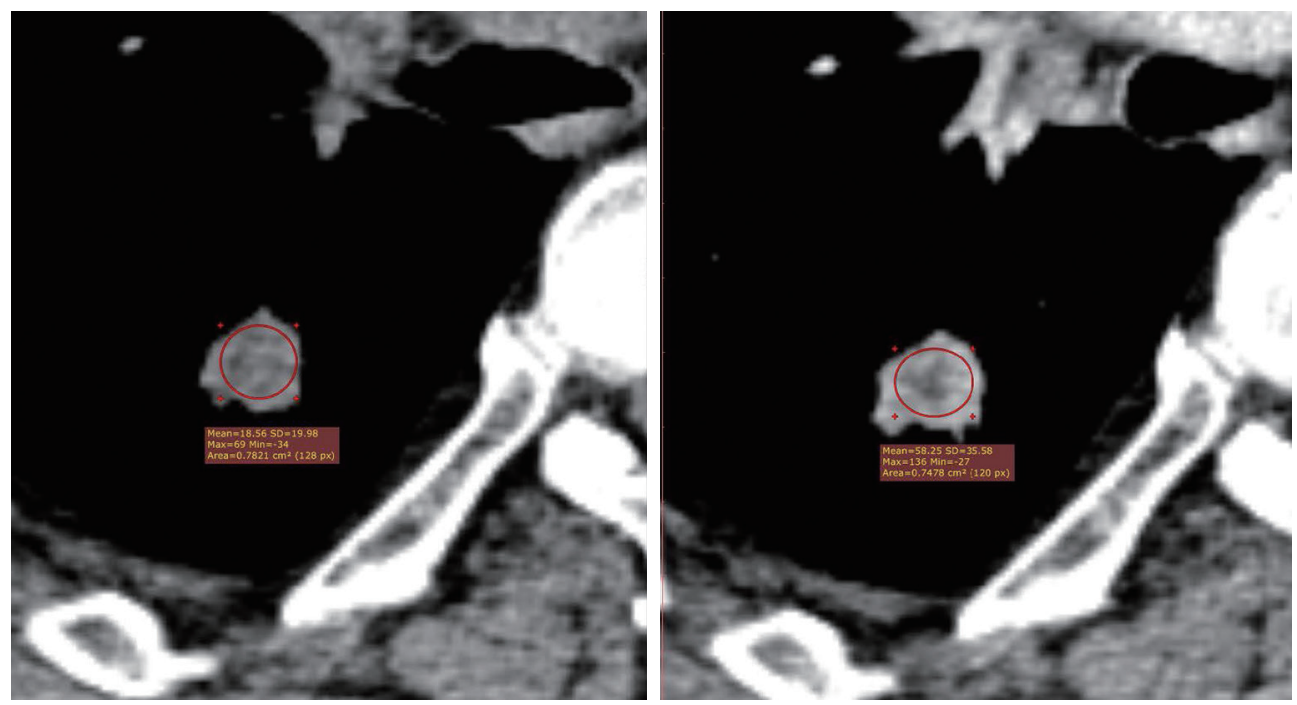

Figure S12 A 60 years old male patient with a solid irregular, lobulated tumor $\left(23 \times 19 \mathrm{~mm}^{2}\right)$ located in the right lower lobe. The mean density of the nodule 12 was 18.6 Hounsfield Units on CT without iodine contrast, and a density of 58.3 Hounsfield Units after contrast (uneven-enhancement). Radiologist's diagnosis: malignant; CART model classification: ST3; Histology: squamous cell carcinoma. 

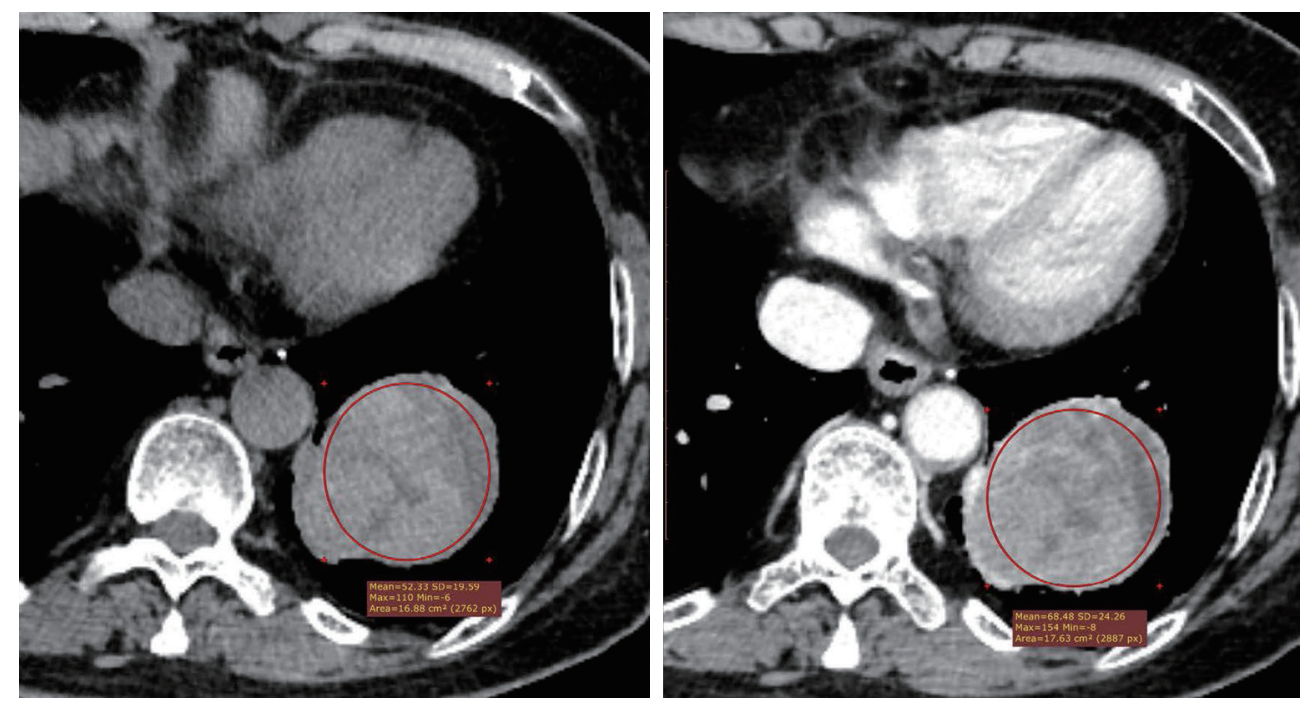

Figure S13 A 78 years old female patient with a solid round, smooth tumor $\left(60 \times 51 \mathrm{~mm}^{2}\right)$ located in the left lower lobe. The mean density of the nodule 16 was 52.3 Hounsfield Units on CT without iodine contrast, with uneven-enhancement 68.5 Hounsfield Units after contrast. Radiologist's diagnosis: probably benign; CART model classification: ST2; Histology: sclerosing.

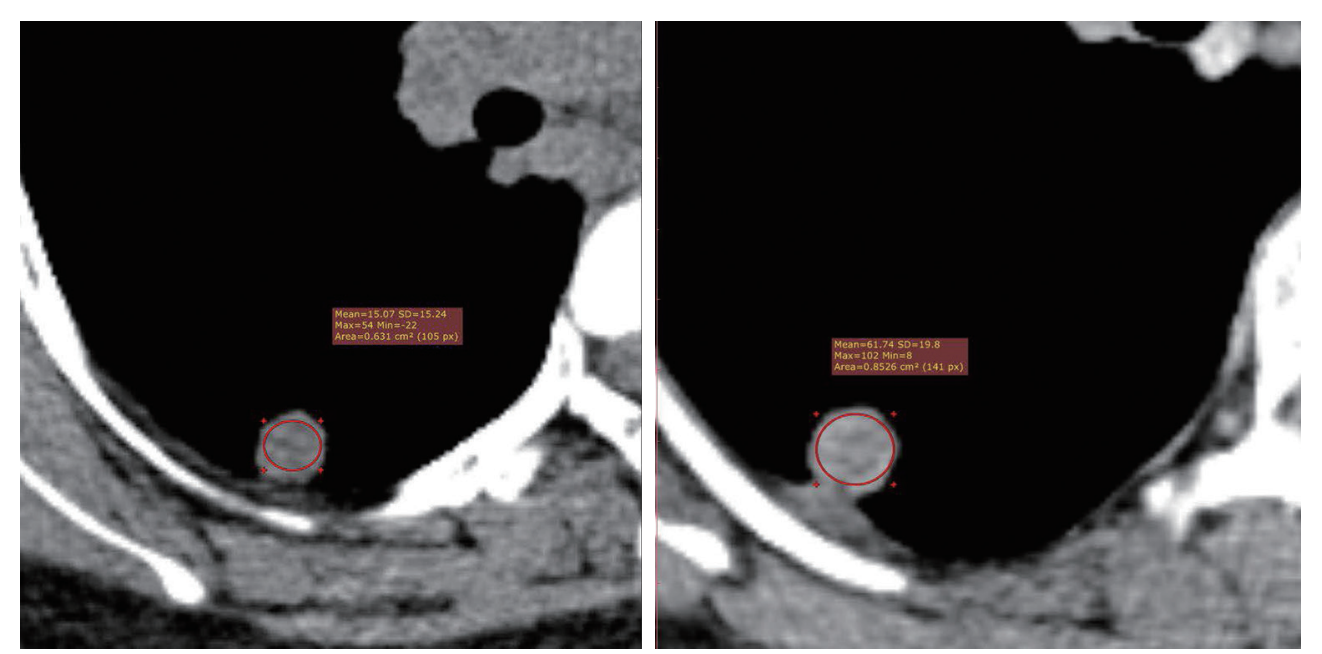

Figure S14 A 56 years old female patient with a solid round, smooth tumor $\left(18 \times 16 \mathrm{~mm}^{2}\right)$ located in the right lower lobe. The mean density of the nodule 20 was 15.1 Hounsfield Units on CT without iodine contrast, and uneven-enhancement 61.7 Hounsfield Units after contrast. Radiologist's diagnosis: Probably malignancy; CART model classification: ST2; Histology: adenocarcinoma. 